\title{
DATA USE IN THE CLASSROOM
}

\section{The Challenges of Implementing Data Based Decision-Making at the School Level}

\author{
Christopher Thorn \\ University of Wisconsin-Madison, Wisconsin Center for Education Research, $1025 \mathrm{~W}$. \\ Johnson, St., Madison, WI 53706, USA
}

\begin{abstract}
Systemic efforts to implement database decision-making at the school-level and classroom-level face several challenges. First, most data available within district information systems are limited to operational needs of schools and the district. Second, educational organizations have little experience integrating complex data into their decision-making processes. Third, while large-scale assessment and accountability data are more generally available for gauging the performance of educational systems, there are major differences between the evidence used for external accountability systems and the data needed for making instructional decisions on a daily basis in the classroom.
\end{abstract}

Key words: Decision support, educational management

\section{INTRODUCTION}

This paper will examine problems school-level staff encounter when attempting to implement data-based decision-making reform efforts, specifically those decisions that influence teaching and learning in the classroom. Many schools and districts are exploring data-driven decisionmaking as a solution for improving resource allocation and instructional program decisions. One of the most challenging problems policy makers and educators face in attempting to implement curriculum reforms is that intervention decisions are made at least one organizational level above that of the teachers - the persons actually engaged in instruction.

The original version of this chapter was revised: The copyright line was incorrect. This has been corrected. The Erratum to this chapter is available at DOI: 10.1007/978-0-387-35689-1_19 
Any systemic effort to implement a focus on database decision-making at the school-level and classroom-level faces several challenges. First, most data available within district information systems are limited to what has been deemed important for the operational and accountability needs of schools and the district. These data include attendance, discipline, and basic demographic data. District systems will also contain detailed information about human resources, budgets, and other business processes. Typically, the only outcome data available are the results from centrally administered tests (which are often annual events) and grades. While this data is useful to help frame annual analysis of school-level, classroom-level, or student-level outcomes, it is inadequate for making mid-course or interim instructional decisions within a single grade/marking period.

Second, while the issues involved in successful database decision-making are just beginning to be discussed in the literature on educational administration and assessment, an important and growing body of relevant work is emerging from business schools around the world. These studies range from considerations of the role of experts in organizational learning (Albert \& Bradley 1997) to multi-dimensional representations of the lifecycle of knowledge (Boisot 1998). Educational journals tend to be focused on application. For example, School Administrator recently published an entire edition (April 2001) dedicated to data-driven decisions. This work addresses systemic reform concerns that help to provide both the technical and information resources necessary to support school-level databased decision-making.

Third, while large-scale efforts to make assessment and accountability data more generally available do provide some insight into the performance of an educational system, there are major differences between the evidence used for external accountability systems and the data needed for making instructional decisions on a quarterly, weekly, or daily basis in the classroom. The large gap between the time horizons of state-level testing and the more immediate needs of program administrators and individual teachers in the classroom means that data needs and rules of evidence will be commensurately divergent.

\section{APPROACHES TO UNDERSTANDING DECISION-MAKING AND KNOWLEDGE WORK}

There is a growing literature on information seeking, information processing, and information use that provides insights into how individuals and groups identify information needs and then respond (or choose not to respond) to those needs. This work draws on and can be used to frame other 
work in the areas of group decision-making, knowledge management, and the human factors of decision support systems.

One recent study of information seeking on the web provides an excellent synopsis of what the authors call an integrated model of human information seeking (Choo et al. 2000) summarizes this model. The important aspects of the model for this paper are intersections between the different behavioural areas - the identification of informational needs, seeking to fulfil those needs, and use of information to address the identified needs. The three points outlined in the introduction can be addressed through this model. I will use a school improvement team attempting to create an improvement plan for math instruction as an example case to illuminate several aspects of this information-seeking model. The anecdotes described in this case are taken from lessons learned from working with school improvement teams and from school improvement planning documents.

\section{$2.1 \quad$ Information needs}

First, the identification of information needs is a primary problem in any type of school reform or curriculum improvement. As indicated above, much of the data available from district information systems is limited to data useful to make district level decisions. The granularity ${ }^{1}$ and temporal resolution ${ }^{2}$ of the data available severely restrict its usefulness for different user groups. In the case of an effort to understand current performance and how that performance relates to school and district goals, the School Improvement Planning [SIP] team can examine district accountability reports for aggregate data and school-level and individual-level score sheets from math component of the annual standardized math achievement test and compare the results on these metrics to goals set by the school, district, and/or state for their desired or expected performance.

In this situation, the SIP team attempts to frame a problem in terms of a gap between the observed math performance of the students and outcomes targeted by the accountability goals. At this point, the problem has been

${ }^{1}$ Granularity is a term used to describe the level of aggregation of data. For example, attendance data could be listed as follows in increasing finer granularity - days absent this year, days absent this semester, days absent this week, or periods absent this day. The finer the grain size, the more detailed the analysis can be. The tradeoff however, is that the finer the granularity, the more data one must manage.

${ }^{2}$ Temporal resolution refers to the span of time to which a particular datum or data set refer. Annual test scores have the temporal resolution of one year. Weekly spelling test scores have a temporal resolution of one week. The temporal resolution of a particular type of data makes it more or less useful for measuring the state of or the change within a system over a given span of time. 
defined as a gap. Typically, the data contained in the accountability system is not sufficient to diagnose the cause of the performance gap. Information on curriculum, teacher ability, classroom resources, attendance, discipline problems, contributing social/home factors, etc. comes from many different sources. The next step is a decision-making process that produces one of two outcomes. Either the SIP team identifies gaps in their knowledge about what might explain the performance gap and initiates a search for additional information or the choice is made to avoid the problem. This avoidance might take the form of a simple denial of the problem - bad tests, high student turnover, etc. - or the team might choose a solution based solely on the easily available aggregate data and make an intervention decision based on incomplete (or nonexistent) data.

\subsection{Information seeking}

This step is the most intriguing part of the information processing model when examining school level decision-making and the use of decision support tools. Once an information gap is identified, the SIP team is then faced with expressing a model of learning that encompasses the outcome and includes factors that the team feels contribute, either directly or indirectly, to that outcome. It is at this point that they search for new sources of information. ${ }^{3}$ This data may reside in teacher grade books, lesson planning software, local databases, locked filing cabinets, etc. The team is faced with the task of assembling data that complies with the model of learning they have expressed. One important dimension of the information seeking activity is differential ease of access. Some data will be readily available in a central data store or in the school office. Other data will be in paper form in or on an individual teacher's desk. Resolving access issues is a constant struggle, since the resource needed to acquire hard-to-find or manage data may exceed its value in the analysis.

Issues of the data's reliability and validity of the data are also important components of the discussion, particularly if students or teachers with substandard performance are to be exposed to serious consequences. Inclass assessments, for example, may be entirely valid measures in that they accurately represent the content of the curriculum and related learning standards. The fact that they are scored by different teachers and that the sample sizes are small (individual classrooms) means that scores will not be

${ }^{3}$ Some examples include; attendance and tardiness data for individual students, discipline data, results of in-class assessments, seniority and educational level of teachers, quality of the curriculum, quality and availability of professional development in the area in question, etc. 
reliable. It is at this point that tools for supporting data collection and data exploration are most important.

\subsection{Information use}

The information use portion of the model describes the combination of the identified needs, the acquired information, and its translation into action. This is the area where the identification of gaps in student understanding or in teacher professional development are codified based on the gathered information and a plan is implemented to address the shortcoming.

Information use interacts with human tendencies to engage in maintenance of the current practice and accept existing norms of behaviour or to change them. There are many instances where school reform initiatives challenge existing practices, allocation of resources, and the skills of teaching professionals. It is only in gathering appropriate information that newly defined problems can be examined and the results of new efforts can be evaluated. School reform efforts interact with all areas of this model. Policy makers and implementers must recognize these social structures and practices in order to support the desired behaviour and achieve the target outcomes.

\section{DECISION-MAKING MODELS}

(Choo et al. 2000) provide a second model that parallels the human information-seeking model. This model provides a short hand for a larger decision-making model. The authors argue that sensemaking is the first important activity. This is the process of coordinating beliefs with extant information. The sensemaking process often requires that one engage in knowledge creation - bringing external information together with implicit and explicit knowledge about the current problem. Knowledge creation serves to fill gaps in the sensemaking process - it fills in gaps in understanding. Finally, one then moves on the decision-making process that integrates new understanding with existing rules and procedures that guide action.

Knowledge-based systems allow users to explore many different alternatives in a series of "what if" models. Use of the environment itself can contribute to the user's personal skills as an analyst (Jasinski \& Huff 2002). School reform efforts encourage school-level staff to make informed decisions that both operationalize their own long-term strategies for student learning and professional growth as well as align with larger district and 
societal goals. Decision support systems can help to make sense of the overwhelming complexity of large data collections.

Another important benefit that decision support systems should provide is supporting users as they search for and explore the attributes of alternative strategies. The search for alternatives is one of the most important activities in which a school improvement team engages. Shortcomings of existing outcomes lead to an identification of gaps, failures, and needs.

\subsection{Sensemaking}

In the case of our example, sensemaking is one of the core activities that is often overlooked in school improvement planning. Planning templates are usually created at the district level as a part of a district's accountability system. Outcome metrics are annual scores or percentiles that apply a single accountability model to all schools. The sensemaking process provides a framework for local decision-making. In this example, when faced by declining math scores a SIP team might look at the subscale scores on that test for both grade cohorts and individual students to see if they observe score declines across the board or in specific areas. This would allow the team to reconcile their local beliefs about the quality of student work and the relationship of existing classroom practices to that work. This process mirrors the information needs process in that is through the identification of what is to be studied that information needs emerge.

\subsection{Knowledge creation}

The knowledge creation process again can be seen as parallel to information seeking. Knowledge is created through assembling individual understanding, bringing in outside information in the form of possible alternatives, lessons learned, etc. and relating that to information already in use. In the example case, this is likely to take the form of exploring what the math test actually measures. This information is then combined with an understanding of the relevant teaching and learning standards to compare what is measured with what is being taught. This synthesis then frames the gaps in the test and the gaps in the curriculum. This gap analysis combined with the sensemaking process provides a framework for crafting new approaches to the problem. 


\subsection{Decision-making}

Now that necessary new knowledge has been created and the SIP team has a clear understanding of the instructional needs of the students and the areas that the test does not measure, it is time to examine a series of alternatives that would achieve the learning goal. This is another area where teams are likely to find great frustration. Often, schools have few resources for identifying alternative approaches to instructional challenges. They often have to rely on a few professional development days, personal experience, and limited contacts with other professionals outside of the school year. However, the team that takes the sensemaking process seriously - perhaps by neglecting the narrowly focused SIP framework - is often better prepared to make a more concrete statement and choose a plan that fulfils their understanding of the needs in the current situation.

These models are not presented as a panacea for decision-making challenges, but they do provide a more human and responsible framework for understanding the dynamics of successful improvement planning at the school level.

\section{TECHNICAL CAPACITY}

There is no single approach to supporting better decision-making at the school level. There are, however, a number of approaches to data collection and analysis that might support the development of more sophisticated questions and a more rigorous search for alternatives. As discussed above, aside from basic demographic data, state- or district-level testing is often the only common assessment metric (aside from grades) that is available for analysis of student outcomes. In the case of elementary schools, in particular, much of this data is kept in paper form in teacher grade books and lesson plans.

Centralized classroom record keeping is possible in some environments. The majority of school classrooms have Internet-connected computers and would, therefore, potentially have access to remote systems for entering classroom data and receiving reports. According to a recent National Center for Education Statistics [NCES] study, the availability of networked computers in classrooms has increased substantially.

Since 1994, when 3 percent of instructional rooms had computers with Internet access, public schools have made consistent progress: in fall 2000 , 77 percent of instructional rooms were connected to the Internet, up from 64 percent in 1999 . However, in 2000 , as in previous years, there were differences in Internet access in instructional rooms by school 
characteristics. For example, in schools with the highest concentration of students in poverty, a smaller percentage of instructional rooms were connected to the Internet (60 percent) than in schools with lower concentrations of poverty ( 77 to 82 percent of instructional rooms) (Cattagni \& Farris 2001).

While schools and students in urban districts continue be relatively disadvantaged in their access to Internet technologies in the classroom, there have been substantial improvements in technical infrastructure. To cite a regional example, both the Madison and Milwaukee public school systems have made major improvements in network infrastructure and have increased the number of networked computers available for administrative and instructional uses. Unfortunately, the technology alone is not sufficient to support robust data based decision-making.

\section{ORGANIZATIONAL CAPACITY}

Technology in the classroom is important, but more important is an expanded vision of what constitutes data. One recent article described Palisades School District, Pennsylvania in which parents, teachers, and administrators conduct two, short, one-on-one interviews with over half of the students in the district (Barnes 2001). This data was collected to provide an additional perspective on how the district was making progress to meet its learning goals. ${ }^{4}$ Teachers use the feedback they get from students to reflect on instructional practices, refine teaching approaches, and aid them in selecting curricular materials. An interview team visits a single school and spends the day doing interviews. At the end of the day, the team meets with the principal and the teaching staff to summarize the comments made by the students. The interview notes are left at the school to provide teachers with the opportunity to engage in a more detailed analysis of the responses. The survey was designed to explore and make clear the districts expectations for particular areas of the curriculum in each year. In this way, the administration of the survey both reinforced the districts goals and gathered detailed information about students' progress towards meeting those goals. The fact that the walk-throughs are repeated twice a year and occur each year allows teachers and administrators to observe change more clearly and provides a longitudinal view of student experiences that is often lost as student progress from grade to grade with little interaction between grade cohorts.

${ }^{4}$ The 15 minute interviews are based on a structured protocol that is adjusted to be grade appropriate. 
The importance of active, focused, local school reform is made even more pressing and relevant by a recent study that shows that the impact of teacher classroom practice is equally important as socio-economic background and ethnicity - based on NAEP 1996 test data (Wenglinsky 2002). Educational improvement planning is happening at the school level and has the potential to have a large positive impact on student learning. One of the things that are missing is an open, reflective, decision-making process that would support school administrators and local teaching staff in their desire to engage in meaningful, locally-led improvement.

\section{CONCLUSIONS}

There is a long literature on decision-making. The Handbook of Social Psychology provides an excellent cross-disciplinary overview and describes structure versus process, riskless versus risky choices, and normative versus descriptive models of choice as the important dimensions of decisionmaking (Abelson \& Levi 1985). These authors suggest several approaches that would improve the quality of decision-making. There are several recommendations that would be particularly relevant for this case (see Abelson \& Levi 1985: 274-293).

First, improved access to relevant data - whether the data is locally held or extracted from a district data store - would reduce the school improvement team's uncertainty about the important dimensions of the problem at hand. This clearer view of the gap in expected outcomes would allow the team to craft a more targeted and appropriate response.

Second, providing access to high quality professional development materials in the form of case studies that link practice, materials, and outcomes would help the team expand its search for alternatives outside the narrow box of improving a particular score.

Third, review incentives that reinforce short-term gains over long-term structural improvements. The current climate in many urban schools is one of improve this year or else. Value-added analyses that relate performance to the rate and/or amount of improvement for particular groups of students should be explored as a method for rewarding movement towards a goal and provide incentives for improvement to both high and low performing schools.

Finally, district school improvement planners need to recognize that providing school leaders with highly constrained choices about how to show improvement reduces these leaders' ability to think creatively and limits their ability to search for alternatives that would be most meaningful for their particular conditions. 
State and district level administrators need to provide leadership by showing that they value appropriate use of data to support school improvement. They also need to provide professional development opportunities and personal mentoring necessary to make their staff comfortable with the process of needs analysis and program evaluation at the school level. While political accountability and its related metrics are important they are too far removed from instructional practices and provide very little relevant feedback for local, classroom-level improvements.

\section{REFERENCES}

Abelson, R.P., \& Levi, A. (1985). Decision making and decision theory. In The Handbook of Social Psychology (3rd ed., Vol. 1), Aronson E. \& Lindzey G. (Eds.),. Random House, New York

Albert, S., \& Bradley, K. (1997). Managing Knowledge: Experts, Agencies, and Organizations. Cambridge University Press, Cambridge.

Barnes, F.V.M. (2001). Data analysis by walking around. The School Administrator, 58 (April, 4), pp. 20-25.

Boisot, M. (1998). Knowledge Assets: Securing Competitive Advantage in the Information Economy. Oxford University Press, Oxford.

Cattagni, A., \& Farris, E. (2001). Internet Access in U.S. Public Schools and Classrooms: 1994-2000 (Print available, PDF File). U.S. Department of Education, National Center for Education Statistics, Washington, D.C.

Choo, C.W., Detlor, B., \& Turnbull, D. (2000). Web Work: Information Seeking and Knowledge Work on the World Wide Web (Vol. 1). Kluwer Academic Publishers, Boston.

Jasinski, D.W., \& Huff, A.S. (Eds.). (2002). Using a Knowledge-based System to Study Strategic Options. Sage Publications Ltd, London.

Wenglinsky, H. (2002). How schools matter: The link between teacher classroom practices and student academic performance. Education Policy Analysis Archive, 10(12). 


\section{SECTION 2}

ICT FOR MANAGING EDUCATIONAL INSTITUTIONS 